\title{
ИННОВАЦИИ И СТРАТЕГИЯ - КЛЮЧЕВЫЕ ЭЛЕМЕНТЫ ЦИФРОВОЙ ТРАНСФОРМАЦИИ БИЗНЕСА
}

\author{
(C) 2019 Евдокимов Анатолий Николаевич \\ кандидат экономических наук, доцент кафедры менеджмента \\ Самарский государственный экономический университет, Россия, Самара \\ (C) 2019 Сураева Мария Олеговна \\ доктор экономических наук, профессор кафедры менеджмента \\ Самарский государственный экономический университет, Россия, Самара \\ E-mail:Panda63d@mail.ru
}

Многие современные компании находятся на пороге цифровой трансформации или, по крайней мере, инвестируют средства в цифровые технологии, ресурсы и повышают квалификацию работников в рамках своей стратегии цифровой трансформации. Начиная цифровые преобразования своего бизнеса, компаниям необходимо использовать технологии для стимулирования инноваций, а не просто для улучшения текущих процессов, поскольку внедрение инноваций открывает огромные перспективы для роста. Инновации должны стать частью стратегии цифровой трансформации. Авторы рассматривают актуальный для многих компаний вопрос с чего начинать программу цифровой трансформации, какие действия необходимо предпринимать, чтобы разработать эффективную стратегию цифрового преобразования. Авторы формулируют основные составляющие необходимые для успешной цифровой трансформации компании.

Ключевые слова: цифровая трансформация, цифровая стратегия, управления изменениями, бизнес-модели, инновации, цифровые технологии, партнерские отношения, цифровые возможности.

Ведущие компании продолжают овладевать цифровыми инновациями и разрушать устоявшиеся отрасли в этом процессе. Современные компании начинают осваивать электронную коммерцию, поэтому остальных это заставляет сосредоточиться на цифровой трансформации ускорении процессов и компетенций, для того чтобы в полной мере использовать преимущества цифровых технологий.

Цифровая трансформация - это процесс переосмысления своей бизнес-модели или бизнес-процесса в свете доступности цифровых технологий. Это требует координации всей компании, так как она применяет новые технологии, чтобы фундаментально изменить способ ведения бизнеса.

Компаниям необходимо использовать новые технологические возможности и организационные изменения для создания опыта, который адаптируется к меняющимся потребностям клиентов. Все больше и больше, исключительный опыт клиентов является ключевым дифференциатором в цифровом бизнесе, а процесс цифровой трансформации должен руководствоваться цифровой стратегией, ориентированной на клиента [1].
В результате многим компаниям еще предстоит принять меры по капитализации цифровых технологий. Циклы развития цифровых технологий чрезвычайно быстры - намного быстрее, чем для большинства традиционных продуктов и услуг. Учитывая широкое распространение, низкую стоимость входы и потенциальное влияние цифровых технологий, необходимо, чтобы современные компании действовали уже сегодня, запуская новый цифровой продукт или услугу и оцифровывая внутренние процессы [2]. Это означает, что они должны осуществлять гораздо более быстрые процессы развития и становиться гораздо более удобными в принятии решений в условиях неопределенности. Таким компаниям необходимо использовать стратегический подход и инновации, используя циклы построения-оценки-обучения, даже если они не совсем уверены в результате.

Компаниям необходимо сосредоточиться на экспериментальных испытаниях и прототипах, которые могут быть разработаны и развернуты, оценены на производительности и соответственно масштабированы (или закрыты). Они должны воздавать свои цифровые возможности через прямой опыт. Для этого предстоит управ- 
лять несколькими инициативами, пробуя новые бизнес-модели. Для успеха такого подхода методом проб и ошибок требуется структурированная методология трансформации, состоящая из трех шагов: обеспечение быстрых побед с самого начала, масштабирование успешных инициатив и лидерство в поддержании изменений [3]. Вместе эти шаги могут помочь руководителям определить, с чего начать, как управлять процессом и как генерировать устойчивый прогресс с их цифровыми преобразованиями.

Компании, стремящиеся к цифровым технологиям, исходят из разных исходных позиций, с различными возможностями, обстоятельствами и степенью амбиций. Например, некоторым компаниям потребуется полная трансформация своих операций, процессов и бизнес-моделей для того, чтобы полностью использовать цифровые технологии и получать доход, Другим, возможно, потребуется только повысить эффективность за счет реинжиниринга существующих бизнес-и операционных моделей [4]. Независимо от того, насколько амбициозны цифровые усилия, компаниям необходимо начать с одной их нескольких областей: улучшение опыта клиентов, предложение новых цифровых продуктов и услуг, а также оцифровка внутренних процессов.

Чтобы улучшить качество обслуживания клиентов, например некоторые энергетические компании начинают предлагать мобильные приложения, которые позволяют клиентам проверять счета и получать данные счетчиков, более продвинутые предложения от торговых сетей позволяют клиентам отслеживать списки покупок и заказывать товары вне магазина через портал электронной коммерции на своем смартфоне. А некоторые туристические сайты отправляют обновления статуса рейса, время вылета, подтверждение аренды автомобиля, направления в отель и другую информацию, связанную с поездкой на телефоны или электронную почту - все последовательно, для того, чтобы клиент прибыл точно в нужное время. Автопроизводители тоже улучшают продажи, используя цифровые каналы для передачи информации об автомобилях клиентам, когда это им необходимо или в момент покупки авто.

Далее компании могут использовать новые предложения и услуги, основанные на данных, которые дополняют существующие активы и бизнес-модели. Данные предложения не просто должны улучшить ценностное предложение для клиента, они должны превосходить его и помогать компании расширяться в новые области цепочки создания стоимости [5]. Например, многие банки переходят от обработки платежных транзакций к таким услугам, как покупки, сравнение продуктов, скидки и рейтинги. Точно также телекоммуникационные компании начинают предоставлять своим клиентам услуги потокового видео и электронной коммерции, например к базовому обслуживанию. В промышленности в настоящее время компании используют датчики в капитальном оборудовании для предупреждения пользователей о проблемах технического обслуживания, что позволяет произвести ремонт вовремя и избежать более крупный проблем.

Независимо от того где будет компания использовать цифровые технологии, это ей позволит повысить эффективность и точность внутренних процессов, снизить затраты, а также позволит использовать более подробную аналитику [6]. Поэтому огромное значение имеет скорость таких преобразований независимо от того, начинает ли компания свою цифровую трансформацию с улучшения клиентского опыта, разработки новых продуктов или услуг или улучшения внутренних процессов или комбинации всех трех. Вместо того, чтобы пытаться усовершенствовать новые продукты или услуги компании на этапе разработки, необходимо стремится быстро вывести их на рынок, заложив в них достаточно функций, чтобы сделать их функциональными. Это позволяет компании минимизировать свои инвестиции, тестировать новые продукты и услуги в реальном мире (а не в искусственных условиях, таких как фокус-группы), и совершенствовать их с помощью обратной связи. Например, начальные версии приложений и интернет-магазинов часто довольно просты, с новыми функциями и функциями, добавленными с течением времени, в зависимости от того, как продукт используется клиентами.

Итак, после того, как компания определила свои наиболее важные цифровые приоритеты и получила несколько быстрых побед, она сталкивается с проблемой масштабирования. Для решения данного вопроса имеется несколько рычагов, правильные из них зависят от уровня амбиций компании, от силы уже существующих цифровых возможностей и внешних рыночных факторов. Одним из быстрых способов масштабирования цифровых инициатив является при- 
обретение цифровых талантов на временной основе, а затем их внедрение их. По мере того как компания внедряет талант, она может создавать цифровые единицы, которые в дальнейшем ей будут служить центром передового опыта и внутренним хранилищем ее текущего мышления о технологии [7]. Данная модель позволяет компании ограниченно развивать цифровые возможности, но позволит ей развивать свой собственный опыт.

Другим более смелым подходом можно считать создание внутреннего инкубатора для использования возможностей, уже разработанных другой компанией - предпочтительно предпринимательской. Это возможно сделать с помощью стартапов на ранних стадиях, совместного предприятия или прямого приобретения. Если компания принимает активное участие, инвестируя и развивая новое предприятие, с целью культивирования цифровых возможностей, которые она может в дальнейшем использовать. Такой подход позволяет компании быстро переходить на цифровые технологии и формировать стартап-менталитет, ограничивая при этом риск сбоев и влияние на существующие операции [8]. Однако для этого требуется капитал, готовность действовать как инвестор и правильная степень надзора.

Следующим не менее важным шагом является правильный набор внутренних ресурсов. Даже успешные пилотные проекты не смогут реализовать свой потенциал без организационной поддержки. Компании необходимо развивать эти проекты, чтобы они стали устойчивыми в масштабе. Талант и культура также имеют решающее значение. Компании важно нанимать потенциальных сотрудников, обладающих навыками в таких областях, как гибкая разработка и аналитик.

Цифровые инициативы требуют различных возможностей и требуют гораздо более быстрых циклов развития, и они часто выигрывают от того, что им отводится четкое место в организации наряду с выделенными ресурсами.

Наконец, компаниям необходимо внедрять силовые процессы управления изменениями. Ключевой задачей будет увязка цифровых инициатив с налаженными операциями компании и обеспечение того, чтобы руководители и сотрудники продолжали сотрудничать и распространять цифровые успехи или неудачи по всей организации, поскольку даже неудачи дают воз- можность учиться.

Прежде чем компании начать свое цифровое путешествие, она должны оценить свою готовности, изучив доступность и качество данных, свою IT- архитектуру, свои возможности в области инноваций, а также свою общую культуру и готовности к изменениям [9]. Управленческой команде необходимо тщательно работать с персоналом, чтобы оценить опыт сотрудников, а том, числе в таких областях как программирование, внедрение IT, цифровой маркетинг, социальные медиа и анализ данных.

Когда компании начинают процесс цифровой трансформации, они могут формировать стратегию, которая, как правило, включает в себя покупку современных технологий и создание команды для ее реализации. Безусловно, эти шаги важны, но на практике компонентов, работающих вместе ради общей цели гораздо больше. Сформулируем основные компоненты, способствующие успешной цифровой трансформации.

- Cтратегия: необходимо реализовывать ее так, чтобы было согласование с направлениями трансформации.

- Лидерство: поскольку цифровая трансформация требует глубоких организационных изменений и координации, она становится более эффективной, когда ведется с верхнего уровня бизнеса.

- Вовлеченность: необходимо чтобы все были вовлечены в процесс трансформации, а не только инноваторы.

- Инновации: главным ориентиром трансформации должен быть прогресс.

- Технология: ее необходимость заключается в том, чтобы произвести внутри компании изменения от внешней организации или другим путем.

- Сторонние партнеры: поиск партнеров, у которых есть определенные сильные стороны в ваших областях слабости. Структурируйте отношения как партнерские отношения с ожиданием обмена знаниями и частым общением. Это позволяет избежать риска создания изолированной информации между несколькими поставщиками.

- Необходимый объем данных и аналитика: необходимо наладить обратную связь и продолжать цифровую трансформацию на постоянной основе.

Если какая-либо из этих частей отсутству- 
ет, компания может столкнуться с непреодолимыми препятствиями. Поэтому перед началом цифровой трансформации важно определить наличие всех семи компонентов. Сила стратегии цифровой трансформации, бесспорно, заключается в ее масштабах и целях. Менее озадаченные этим вопросом компании, как правило, сосредоточены на отдельных технологиях и имеют оперативные стратегии. Цифровые стратегии в самых зрелых компаниях направлены на преобразование бизнеса.

Распространено заблуждение заключается в том, что цифровая трансформация начинается и заканчивается технологией. Компании не должны определять цифровую трансформацию как просто увеличение инвестиций в IT. Опыт клиентов должен стать движущей силой цифровой стратегии, лежащей в основе трансформации, при условии, что компании хотят видеть значительные выгоды от понимания и вовлечения клиентов.
Таким образом, возможность цифрового переосмысления бизнеса во многом определяется четкой цифровой стратегией. Сегодня технологии тесно интегрировались с бизнесов, чтобы стать чем-то большим, чем оборудование или программное обеспечение. Руководителям, которые готовятся к цифровому будущему, необходимо сделать инновации частью этого будущего. По мере того, как цифровые технологии становятся все более распространенными, а компании продвигаются дальше по пути цифровой трансформации, цифровая стратегия и бизнес-стратегия будут одним и тем же. Цифровая стратегия - это применение цифровых технологий к бизнес-моделям для формирования новых дифференцирующих возможностей бизнеса. Рассматривая множество вариантов развития цифровой трансформации, инновации должны занимать первое место в этом списке.

\section{Библиографический список}

1. Аверьянов М.А., Евтушенко С.Н., Кочеткова Е.Ю. Цифровая экономика. Трансформация отраслей // Экономические стратегии. 2016. Т. 18 (142). С. 52-55.

2. Бийчук А.Н. Цифровая трансформация бизнеса в современной экономике // Экономическая среда. 2017. № 2 (20). С. 14-16.

3. Ванюшкина В.В. Цифровая трансформация маркетинговой деятельности // Известия Санкт-Петербургского государственного экономического университета. 2016. № 1 (97). С. 67-70.

4. Зурин М.В., Светиков Н.Н. Влияние цифровых технологий на трансформацию бизнеса: блокчейн // В сборнике: Проблемы и перспективы развития промышленности России Сборник материалов III Международной научно-практической конференции. Под общ. ред. А. В. Быстрова. 2018. С. 232-237.

5. Коваленко Б.Б. Цифровая трансформация: пути создания конкурентных преимуществ бизнес-организаций // Наука и бизнес: пути развития. 2017. № 9 (75). С. 49-52.

6. Кудряшов А.А., Синицина Е.А., Преимущества трансформации механизмов управления цифровым клиентом // Приволжский научный вестник. 2016. № 8 (60). С. 86-89.

7. Куприяновский В.П., Добрынин А.П., Синягов С.А., Намиот Д. Е. Целостная модель трансформации в цифровой экономике - как стать цифровыми лидерами // International Journal of Open Information Technologies. 2017. T.5. № 1. С. 26-33.

8. Смирнов Е.Н. Эволюция инновационного развития и предпосылки цифровизации и цифровых трансформаций мировой экономики // Вопросы инновационной экономики. 2018. Т. 8. № 4. С. 553-564.

9. Смирнов Н. Цифровая трансформация // Директор информационной службы. 2014. № 12. С. 38. 